\title{
Apnoea, bradycardia, and oxygen saturation in preterm infants
}

\author{
C J Upton, A D Milner, G M Stokes
}

\begin{abstract}
To analyse the effects of apnoea and bradycardia on the oxygen saturation $\left(\mathrm{SaO}_{2}\right)$ of preterm infants and to make recommendations for apnoea alarm limits, polygraphic recordings were made on 89 occasions of 27 preterm infants; 1029 apnoeic episodes were analysed. Reduction in $\mathrm{SaO}_{2}$ was positively correlated with duration of apnoea, but the scatter of results was such that reductions in $\mathrm{SaO}_{2}$ of up to $40 \%$ occurred with apnoeas of less than 10 seconds duration. The median initial $\mathrm{SaO}_{2}$ was significantly lower in those episodes that resulted in bradycardia ( $92 \%$ compared with 95\%), and there was also a significantly greater reduction in median $\mathrm{SaO}_{2}$ (9\% compared with $5 \%$ ).

This study illustrates the difficulty of setting alarm limits for the detection of apnoea. We suggest that rather than simply detecting apnoea it is more appropriate to monitor heart rate and $\mathrm{SaO}_{2}$ in infants with recurrent apnoea.
\end{abstract}

Apnoea of prematurity is one of the commonest problems encountered when caring for very low birthweight babies, and is likely to become more common as survival of such infants improves. ${ }^{1}$ It is also associated with long term morbidity. ${ }^{2}$ Despite this, we have little knowledge of the acute effects of apnoeic attacks on the oxygenation of small preterm infants. Previous studies have used transcutaneous oxygen monitors to measure these effects, but they have slow response times in comparison with the average duration of an apnoeic episode. ${ }^{3-5}$ Pulse oximetry has been shown to be extremely accurate in a neonatal population and overcomes the problem of slow response. ${ }^{6}$

This study was therefore designed to examine the effects of apnoeic attacks on the oxygen saturation $\left(\mathrm{SaO}_{2}\right)$ of preterm infants, as measured by pulse oximetry, and see how this relationship is affected by the presence of bradycardia and treatment with methylxanthines. With this information we hoped to make recommen- many of whom were studied longtitudinally. Median birth weight of the infants was $1140 \mathrm{~g}$ (range 710-1700) and gestational age 29 weeks (range 25-32). Median day of study was 15 (range 1-55) and postconceptional age 32 weeks (range 26-36). There were 16 boys and 11 girls. Infants were receiving treatment with theophylline for apnoea during 45 of the 89 studies. A total recording time of 353 hours was analysed with a median study time of 3.96 hours (range 2:19-5·29).

$\mathrm{SaO}_{2}$, an electrocardiogram, and two signals representing respiratory effort (thoracic impedance and abdominal respiratory inductive plethysmography) were recorded on to tape (Racal Store 4) throughout the study. $\mathrm{SaO}_{2}$ was measured by an Ohmeda Biox 3700 pulse oximeter, which has been thoroughly evaluated for use in neonates. ${ }^{6}$ The probe was sited over the dorsum of the foot and the standard six seconds averaging time for $\mathrm{SaO}_{2}$ was used. This will have smoothed out some of the reductions in $\mathrm{SaO}_{2}$ during short apnoeic attacks but was chosen to cut down on movement artefact, which is more common with a shorter averaging time. The electrocardiographic signal was recorded from a Life Trace 12 monitor using Arbo Pink electrodes, with one placed on each side of the chest and the reference lead on the back or abdomen. Agreement between oximeter wave form and electrocardiographic complex heart rates was checked regularly throughout each study. Thoracic impedance was recorded using an $S$ and $W$ Respiratory 8061 monitor and the electrocardiographic leads mentioned above. Abdominal respiratory inductive plethysmography was recorded from a locally constructed model (Respivest), with a single elasticated band placed at the level of the umbilicus. Two signals of respiratory effort are needed to record apnoeic episodes accurately, ${ }^{7}$ and we have described our system in more detail elsewhere. ${ }^{8}$ Recording was usually started after a feed, once the baby had settled to sleep and the signals had been verified on chart paper.

The polygraphic recordings were later viewed at X16 real time on a storage oscilloscope (Hitachi V-134) and any suspicious episodes played on to a Gould chart recorder at real time and then analysed manually. Apnoea was defined as cessation of breathing movement for at least 10 seconds, or a shorter period if associated with bradycardia of 90 beats/minute or less.

The effects of other variables on $\mathrm{SaO}_{2}$ were analysed using simple and multiple regression. Changes in $\mathrm{SaO}_{2}$ dependent on the presence or absence of bradycardia were analysed by the dations for the setting of alarm limits for apnoea \footnotetext{
detection that would avoid hypoxaemia and so-we hoped-limit later morbidity.

\section{Subjects and methods}

Babies born at 32 weeks' gestation or less were studied. The infants were clinically stable, breathing air at the time of study and were not preselected for the presence of apnoea. Eighty nine studies were performed on 27 infants,

North Street,

Derby DE1 3BA.

Accepted 2 August 1990

Medicine and Surgery, City Hospital

A D Milner

Correspondence to:

Dr C J Upton, Derbyshire Children's
} 
Mann-Whitney $U$ test, and the effects of treatment with theophylline on bradycardia by the $\chi^{2}$ test. Approval for the study was given by the Nottingham ethics committee and informed parental consent obtained.

\section{Results}

A total of 1029 episodes that fulfilled the above

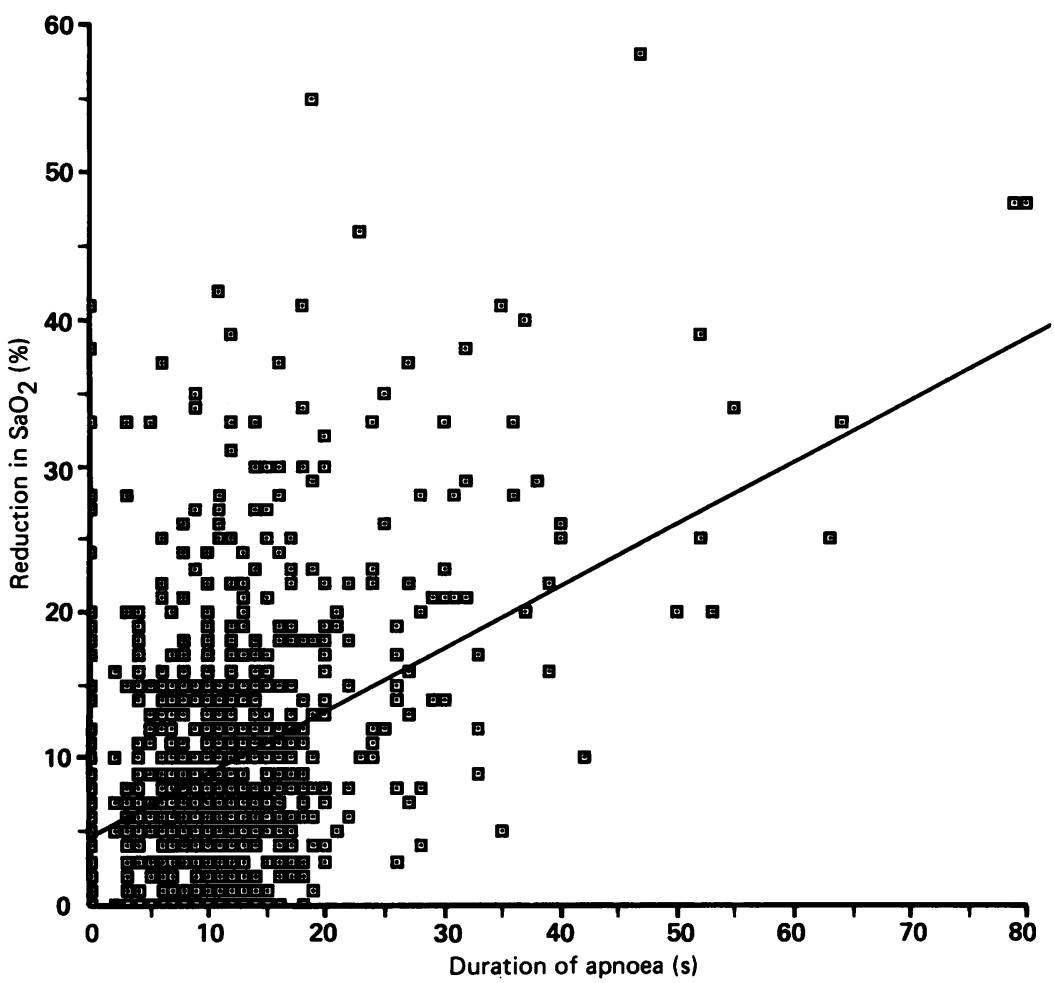

Figure 1 Reduction in $\mathrm{SaO}_{2}(\%)$ plotted against duration of apnoea $(s)$. Reduction in $\mathrm{SaO}_{2}=4 \cdot 57+0.43 \times$ duration of apnoea $(r=0.41, p<0.0001)$.

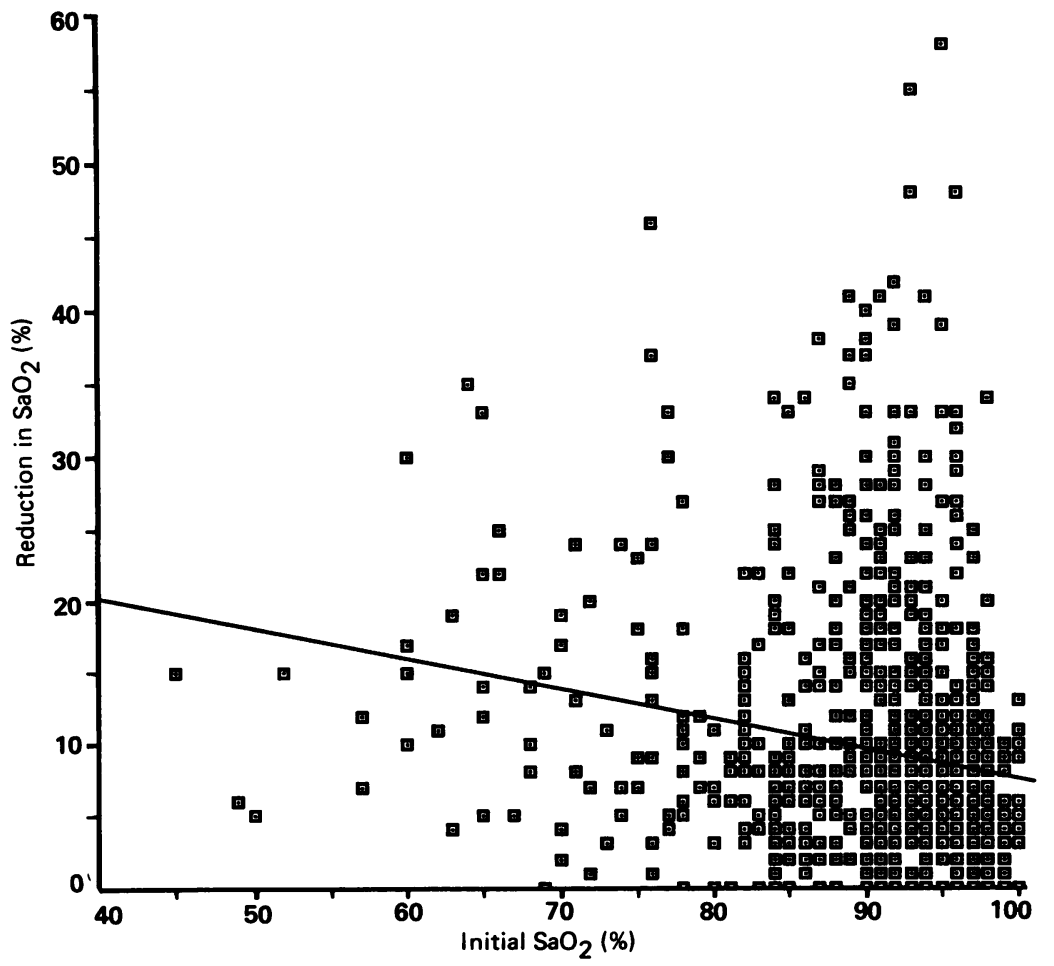

Figure 2 Reduction in $\mathrm{SaO}_{2}(\%)$ plotted against initial $\mathrm{SaO}_{2}(\%)$. Reduction in $\mathrm{SaO}_{2}=28.48-0 \cdot 21 \times$ initial $\mathrm{SaO}_{2}(r=0 \cdot 18, p<0 \cdot 0001)$. criteria were analysed. Of these, 605 were accompanied by bradycardia of which 83 seemed to occur without apnoea. Most of the bradycardias $(522,86 \%$ of the total) were therefore associated with apnoea. In 424 episodes apnoea occurred without bradycardia.

There was a positive correlation between the reduction in $\mathrm{SaO}_{2}$ and the duration of apnoea $(r=0.41, p<0.0001)$ (fig 1). From the regression line one might expect that for an episode of apnoea lasting 10 seconds the reduction in $\mathrm{SaO}_{2}$ would be $9 \%$, and for an episode lasting 20 seconds a reduction of $13 \%$ would be likely. This does, however, hide an enormous variation in the results, and reductions in $\mathrm{SaO}_{2}$ of up to $40 \%$ occurred with episodes of apnoea lasting less than 10 seconds.

The initial $\mathrm{SaO}_{2}$ value before the onset of an episode of apnoea also had an effect on the reduction in $\mathrm{SaO}_{2}$, though it was weak $(\mathrm{r}=0 \cdot 18$, p <0.0001) (fig 2). Infants with poor baseline values of oxygenation, therefore, had greater reductions during apnoeic attacks than those who were well oxygenated. Such a relationship could have been predicted from the haemoglobin dissocation curve. Although the relationship was not strong, it remained significant in a stepwise multiple regression analysis when allowance was made for duration of apnoea, the presence of bradycardia, the frequency of apnoeic attacks, and treatment with theophylline. Of these other variables only treatment with theophylline did not have a significant effect on reduction in $\mathrm{SaO}_{2}$.

\section{BRADYCARDIA}

The baseline $\mathrm{SaO}_{2}$ measurement immediately before an apnoeic attack had a pronounced effect on whether bradycardia resulted during the attack. The median baseline $\mathrm{SaO}_{2}$ measurement was $95 \%$ in those episodes that did not result in bradycardia (interquartile range 92$96 \%$ ) but only $92 \%$ in those with bradycardia (interquartile range 87-94\%). This difference was highly significant $(\mathrm{p}<0.0001$, MannWhitney $U$ test). This effect could have been mediated by the frequency of apnoeic episodes, as when attacks were common, $\mathrm{SaO}_{2}$ may not have had time to return to the baseline value before the onset of the next episode. This is unlikely, however, as apnoea frequency for bradycardic episodes was lower than that for non-bradycardic episodes and there was no significant association between frequency of apnoeic episodes and baseline $\mathrm{SaO}_{2}$ measurements.

To compare the extent of reductions in $\mathrm{SaO}_{2}$ that occurred with and without associated episodes of bradycardia we have analysed separately apnoeic attacks that lasted 10 to 14 seconds. This was necessary because those episodes associated with bradycardia cover the whole range. of duration of apnoeic attacks, whereas those without associated bradycardia had to be at least 10 seconds long to qualify. They became increasingly less common as the apnoea attacks lengthened beyond 20 seconds, as bradycardia was then more likely to occur. There was a highly significant difference in reduction in 
Analysis of variables depending on whether infants were receiving theophylline at the time of study. Values are expressed as median (range)

\begin{tabular}{lll}
\hline & $\begin{array}{l}\text { Infant } \\
\text { receiving } \\
\text { theophylline } \\
\text { (45 studies, } \\
535 \text { episodes) }\end{array}$ & $\begin{array}{l}\text { Infants not } \\
\text { receiving } \\
\text { theophylline } \\
\text { (44 studies } \\
494 \text { episodes) }\end{array}$ \\
& $92(45-100)$ & $94(49-100)$ \\
\hline Initial $\mathrm{SaO}_{2}(\%)$ & $10(0-80)$ & $11(0-31)$ \\
Duration of apnoea (s) & $8(0-58)$ & $6(0-55)$ \\
Reduction in $\mathrm{SaO}_{2}(\%)$ & $6(1-73)$ & $4(1-36)$ \\
No of bradycardic beats & $74(30-90)$ & $77(30-90)$ \\
Lowest heart rate (beats/min) & 74 \\
\hline
\end{tabular}

$\mathrm{SaO}_{2}$ between those episodes of apnoea of 10 to 14 seconds duration that were and were not associated with episodes of bradycardia $(\mathrm{p}<0.0001$, Mann-Whitney U test). Episodes not associated with bradycardia had a median $5 \%$ reduction in $\mathrm{SaO}_{2}$ (interquartile range 3$8 \%, \mathrm{n}=353$ ), whereas those associated with bradycardia had a median reduction of $9 \%$ (interquartile range $5-14 \%, n=138$ ).

TREATMENT WITH THEOPHYLLINE

Analysis of the effects of treatment with theophylline is confounded by the fact that those infants with the worst episodes of apnoea are treated. The differences between variables measured with and without treatment are shown in the table; there is only a small difference between the two groups. Apnoeic attacks that occurred during treatment with theophylline, however, tended to start with a lower $\mathrm{SaO}_{2}$ value, to last longer, to have a greater reduction in $\mathrm{SaO}_{2}$, and to produce a longer episode of bradycardia with a lower heart rate $(\mathrm{p}<0.0001$, Mann-Whitney U test). This clearly shows that treatment with theophylline was given to those infants with the most severe problems and does

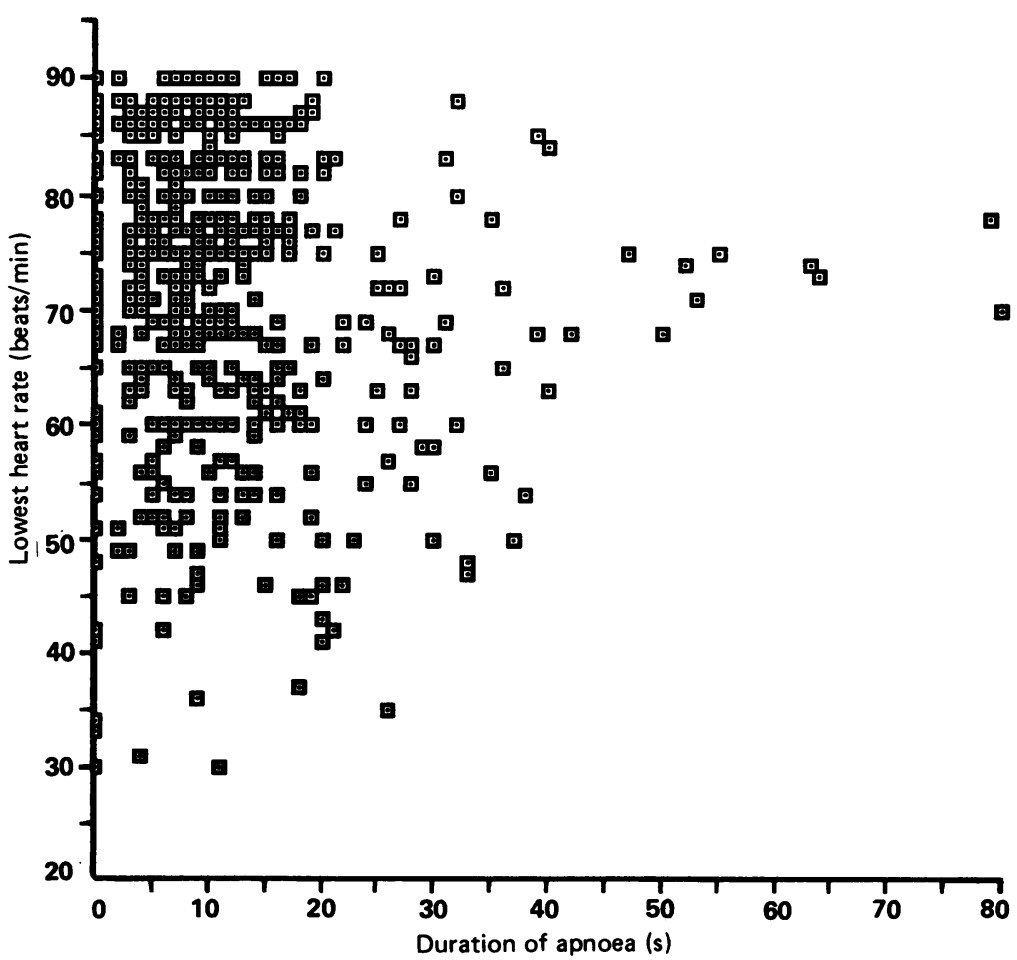

Figure 3 Minimal heart rate during episodes of bradycardia (beats/min) plotted against duration of apnoea $(\mathrm{s})$. Minimal heart rate $=74 \cdot 22-0 \cdot 14 \times$ duration of apnoea $(r=0 \cdot 11$, $p<0.0001$ ) not show that such treatment had a deleterious effect. Theophylline did not, however, reduce the slope of the reduction in $\mathrm{SaO}_{2}$ with respect to the duration of the apnoeic attack. In patients receiving theophylline the slope of the regression line was $0.41(\mathrm{r}=0.45, \mathrm{p}<0.0001)$, and in those not receiving theophylline it was $0.40(\mathrm{r}=$ $0.24, p<0.0001)$. The fact that the association between the reduction in $\mathrm{SaO}_{2}$ and the duration of the apnoeic attack while receiving theophylline is closer than when not, has been noted previously. 9

Treatment with theophylline does not seem to protect against bradycardia either. There was a preponderance of episodes of bradycardia in the group treated with theophylline $(\mathrm{p}<0.001$, $\chi^{2}$ test). This should not be interpreted as meaning that theophylline predisposes to bradycardia, but that the presence of bradycardia is important in the decision to start an infant on theophylline.

\section{ALARM LIMITS}

The absence of respiratory effort is not in itself likely to be deleterious to a preterm infant. Apnoea may be harmful if it produces a change in arterial blood gas tensions, most importantly hypoxaemia. Alternatively, damage may result from hypoperfusion caused by the ensuing bradycardia. Cerebral blood flow velocity in the anterior cerebral artery drops once heart rate falls to below 80 beats/minute. ${ }^{10}$ Ideally, therefore, apnoea alarm limits should be set to prevent a fall in oxygen saturation and to keep the heart rate above 80 beats/minute. The fall in $\mathrm{SaO}_{2}$ that would be acceptable is clearly an arbitrary decision. If one wanted to set an alarm limit to prevent a $10 \%$ drop in $\mathrm{SaO}_{2}$, although the average episode of apnoea that causes this is of 12.5 seconds duration (fig 1 ), the spread is so great that no sensible alarm limit could totally prevent this degree of hypoxaemia. A much shorter alarm limit would, however, result in an unacceptably high number of alarms during apnoeic attacks not associated with falling $\mathrm{SaO}_{2}$.

Similarly, it is difficult to extrapolate a sensible apnoea alarm limit from the degree of bradycardia that is produced. This is because the correlation between minimum heart rate during episodes of bradycardia and apnoea is extremely poor $(r=0.11, p<0.0001)$ (fig 3). Bradycardia of less than 80 may occur with virtually any duration of apnoea, and therefore the minimum heart rate is not helpful in setting apnoea alarm limits. In practice this problem is overcome by routine electrocardiographic monitoring of infants at risk of apnoea.

\section{Discussion}

A poor degree of correlation between the duration of apnoea and the degree of oxygenation has been described by Peabody et al in a study in which they used transcutaneous oxygen monitoring. ${ }^{3}$ There are other important factors that determine the fall in oxygen tension during episodes of apnoea, which they discussed; these include oxygen consumption, metabolic rate, and functional residual capacity. They blamed 
these other confounding variables for producing the poor correlation but, in addition, the slow response time of transcutaneous monitors must have added to the variability in their results. Indeed, Muttitt et al have more recently shown a closer correlation using pulse oximetry. ${ }^{9}$ Their study, however, assumed that short episodes of apnoea were not harmful and only analysed those that lasted 15 seconds or longer. Our results have shown that this is a false assumption and that episodes lasting less than 10 seconds can result in reductions of $\mathrm{SaO}_{2}$ of up to $40 \%$. As a result of including shorter episodes of apnoea in our study, we have shown an even greater degree of correlation between reduction in $\mathrm{SaO}_{2}$ and duration of apnoea.

Another important difference between our study and that of Muttitt $e$ al is that they also monitored nasal airflow, whereas we only assessed external indicators of respiratory effort in detecting apnoea. This is important as in a clinical setting it is the apnoea alarms on these devices that we need to set, and relate to the oxygenation of the infant. Our study shows that the wide scatter of results makes this an almost impossible task, and that trying to relate duration of apnoea to heart rate is even more futile. Routine monitoring of nasal airflow is only done in a few neonatal units and it is interesting to note that when our study is compared with that of Muttitt $e t a l$, the use of airflow did not help to predict reductions in $\mathrm{SaO}_{2}$ from duration of apnoea.

These data suggest that attempts to detect apnoea from external movements are not likely to be effective in preventing hypoxaemia in such infants. We would therefore suggest that a fundamental change is made in the way that we monitor infants at risk for apnoea. The poor correlation between heart rate and apnoea has meant that heart rate monitoring in apnoeic infants has become routine practice. Similarly we suggest that it is more appropriate to measure oxygen saturation in infants at risk to assess the degree of hypoxaemia being produced by the apnoea. The combination of electrocardiographic and $\mathrm{SaO}_{2}$ monitoring would allow the detection of potentially damaging episodes no matter how short or long, rather than of all episodes of apnoea, many of which may be harmless.

It has been hypothesised that apnoea of prematurity may be caused by central depression of the respiratory centre as a result of hypoxia. ${ }^{11}$ The study of Hiatt $e t a l$ has been used to show that such a mechanism is unlikely, as hypoxia was not noted to precede 72 apnoeic attacks. ${ }^{4}$ Our study has shown, however, that the baseline $\mathrm{SaO}_{2}$ measurement is extremely variable and that hypoxia does precede a proportion of our 1029 episodes. Clearly, though, the role of hypoxia in the pathophysiology of apnoea cannot be further elucidated from a study such as ours. It is interesting to note, however, the importance of low baseline $\mathrm{SaO}_{2}$ measurements in the aetiology of bradycardia during an apnoeic attack. Our observation that bradycardia is more likely to occur when an infant is relatively hypoxaemic is supported by the study by Wennergren $e t$ al who showed in older infants that laryngeal chemoreflex bradycardia is potentiated in conditions of relative hypoxia. ${ }^{12}$

As episodes of apnoea that result in bradycardia start with a relatively low $\mathrm{SaO}_{2}$, one would also expect a greater reduction in $\mathrm{SaO}_{2}$ during an episode of bradycardia compared with an episode of apnoea not accompanied by bradycardia. We have shown this, but using a six seconds averaging time on our oximeter we were unable to study the temporal relationship between a fall in $\mathrm{SaO}_{2}$ and the onset of bradycardia as described by Henderson-Smart et al. ${ }^{13}$ They postulated that bradycardia was a peripheral chemoreflex response to falling $\mathrm{SaO}_{2}$. We feel, however, that one should be wary of ascribing cause and effect to this relationship, as bradycardia is more common when there is an obstructive element to the apnoea, ${ }^{14}$ and episodes of apnoea with such an element may also be associated with a more pronounced reduction in $\mathrm{SaO}_{2}{ }^{15}$

It seems, therefore, that a mild degree of hypoxaemia predisposes to both bradycardia and larger reductions in $\mathrm{SaO}_{2}$. The implication of this is that it is important to keep infants with recurrent apnoeic attacks relatively well oxygenated. A delicate balance must be reached, however, to avoid hyperoxaemia, in view of the risks of development of retinopathy of prematurity. Unfortunately pulse oximeters are not reliable at excluding hyperoxaemia. The plateau at the top of the haemoglobin dissociation curve means that small increases in $\mathrm{SaO}_{2}$ above $\mathbf{9 0 \%}$ may be associated with large increases in arterial oxygen tension. Consequently an upper alarm limit of $95 \%$ on the pulse oximeter is unreliable at excluding hyperoxaemia. ${ }^{16}$ It seems that $92 \%$ is a more realistic upper alarm limit for the Ohmeda Biox 3700 pulse oximeter. ${ }^{6}$ Monitors vary considerably, however, and the optimal alarm limits ${ }^{16}$ and accuracy ${ }^{17}$ of different instruments also show wide variation. In addition, factors in the baby, in particular the amount of fetal haemoglobin, will affect the association between oxygen saturation and tension. We think therefore that in a baby with recurrent apnoea arterial blood gases should be checked to confirm hypoxaemia before the ambient oxygen concentration is increased. This may then be correlated with $\mathrm{SaO}_{2}$ and appropriate alarm limits for the individual infant calculated.

In practice, using an Ohmeda Biox 3700 monitor, we suggest an upper alarm limit for $\mathrm{SaO}_{2}$ of $92 \%$ and a lower limit of $82 \%$ as a reasonable guideline for infants nursed in oxygen. For infants nursed in air one is not really concerned with an upper limit of $\mathrm{SaO}_{2}$, and a lower limit of $10 \%$ below the baseline $\mathrm{SaO}_{2}$ measurement seems sensible. We think that greater use of pulse oximetry in infants with recurrent apnoea would allow prompt identification of those with hypoxaemia developing during and after apnoeic episodes. The cautious use of these oximeters would also help to avoid hyperoxaemia during the recovery period in those requiring oxygen for treatment or resuscitation.

We gratefully acknowledge the financial assistance of the Medical Research Council of Great Britain. 
1 Henderson-Smart DJ. The effect of gestational age on the incidence and duration of recurrent apnoea in newborm babies. Aust Paediatr $\mathcal{F}$ 1981;17:273-6.

2 Tudehope DI, Rogers YM, Burns YR, Mohay $H$ O'Callaghan MJ. Apnoea in very low birthweight infants: Outcome at 2 years. Aust Paediatr $\mathcal{F} 1986 ; 22: 131-4$.

3 Peabody JL, Gregory GA, Willis MM, Philip AGS, Lucey JF. Failure of conventional monitoring to detect apnea resulting in hypoxemia. Birth Defects 1979;4:275-84.

4 Hiatt IM, Hegyi T, Indyk L, Dangman BC, James LS. Continuous monitoring of $\mathrm{PO}_{2}$ during apnea of prematurity. F Pediat 1981;98:288-91.

5 Marshall TA, Kattwinkel J. Functional residual capacity and oxygen tension in apnea of prematurity. $\mathcal{F}$ Pediatr 1981;98: $479-82$.

6 Hay WW, Brockway JM, Eyzaguirre M. Neonatal pulse oximetry: accuracy and reliability. Pediatrics 1989;83: 717-22.

7 MacFadyen UM, Borthwick G, Simpson H, McKay M, Neilson J. Monitoring for central apnoea in infancylimitations of single channel recordings. Arch Dis Child 1988;63:282-7.

8 Upton CI, Milner AD, Stokes GM. Combined impedance and inductance for the detection of apnoea of prematurity. and inductance for the detection of apnoea of prematurity.

Early Hum Deo 1990,24:55-63.

apnea: diagnosis by nurse versus computer. Pediatrics 1988; 82:713-20.
10 Periman JM, Volpe JJ. Episodes of apnea and bradycardia in Pe cerebral circulation. Pediatrics 1985;76:333-8.

11 Rigatto $\mathrm{H}$, Brady JP. Periodic breathing and apnea in preterm infants. II Hypoxia as a primary event. Pediatrics 1972;50:219-28.

12 Wennergren G, Hertzberg T, Milerad J, Bjure J, Lagercrantz H. Hypoxia reinforces laryngeal reflex bradycardia in infants. Acta Paediatr Scand 1989;78:11-7.

13 Henderson-Smart DJ, Butcher-Puesch MC, Edwards DA Incidence and mechanism of bradycardia during apnoea in preterm infants. Arch Dis Child 1986;61:227-32.

14 Vyas H, Milner AD, Hopkin IE. Relationship between apnoea and bradycardia in preterm infants. Acta Paediatr apnoea and bradycardia

15 Kahn A, Blum D, Waterschoot $P$, Engelman E, Smets $P$. Effects of obstructive sleep apnoeas on transcutaneous rygen pressure in control infants, siblings of sudden infan death syndrome victims, and near miss infants: comparison with the effects of central sleep apnoeas. Pediatrics 1982;70: 852-7.

16 Bucher H-U, Fanconi S, Baeckert P, Duc G. Hyperoxemia in newborn infants: detection by pulse oximetry. Pediatrics 1989;84:226-30.

17 Severinghaus JW, Naifeh KH. Accuracy of response of six pulse oximeters to profound hypoxia. Anesthesiology 1987; 67:551-8. 